\title{
Recent trends in use of adjuvant chemotherapy in elderly stage II- III non-small cell lung cancer
}

\author{
Takefumi Komiya ${ }^{1}$, Emily Powell ${ }^{2,3}$, Achuta Kumar Guddati ${ }^{4}$ \\ ${ }^{1}$ Medical Oncology, Parkview Cancer Institute, Fort Wayne, IN, USA; ${ }^{2}$ Parkview Research Center, Mirro Center for Research and Innovation, Fort \\ Wayne, IN, USA; ${ }^{3}$ Oncology Research Program, Parkview Cancer Institute, Fort Wayne, IN, USA; ${ }^{4}$ Medical Oncology, Augusta University, Augusta, \\ GA, USA \\ Contributions: (I) Conception and design: T Komiya, AK Guddati; (II) Administrative support: T Komiya; (III) Provision of study materials or \\ patients: T Komiya; (IV) Collection and assembly of data: T Komiya; (V) Data analysis and interpretation: All authors; (VI) Manuscript writing: All \\ authors; (VII) Final approval of manuscript: All authors. \\ Correspondence to: Achuta Kumar Guddati, MD, PhD. Division of Hematology/Oncology, Georgia Cancer Center, Augusta University, Augusta, GA \\ 30909, USA. Email: aguddati@augusta.edu.
}

Background: Although randomized trials demonstrated survival benefit of adjuvant chemotherapy,
previous reports have suggested that its use in elderly populations for early stage non-small cell lung cancer
(NSCLC) was infrequent. The current status of adjuvant chemotherapy in this population is unknown.
Methods: Using the Surveillance, Epidemiology, and End Results (SEER) database, we examined the
incidence of chemotherapy in resected stage II-III NSCLC between 2004 and 2015. Staging was determined
according to the American Joint Committee on Cancer (AJCC) 6th version. Cases were grouped by age
(20-69, 70-79, and 80+). Trends in use of chemotherapy by age group were assessed by univariate and
multivariate analyses. Results: A total of 35,009 cases were selected as surgically resected stage II-III NSCLC. Use of chemotherapy was $66.9 \%, 48.2 \%, 25.0 \%$ in age $20-69,70-79,80+$, respectively. Multivariate analysis demonstrated that younger age [20-69] and recent year [2010-2015] of diagnosis were associated with increased use of chemotherapy. Chemotherapy use increased from 2004 to 2015 by $11.0 \%, 18.3 \%$, and $11.3 \%$ in age $20-69,70-79,80+$, respectively. In the age 70-79 group, increased use of chemotherapy was greater in stage II $(24.3 \%)$ than stage III (14.1\%). Five-year overall survival in age $70-79$ group mildly increased by $7.6 \%$ from 2004 to 2011 .

Conclusions: This study suggests that use of adjuvant chemotherapy in the elderly population increased primarily in age 70-79. Few patients in the 80+ age group received adjuvant chemotherapy even in recent years.

Keywords: Non-small cell lung cancer (NSCLC); adjuvant chemotherapy; Surveillance, Epidemiology, and End Results (SEER)

Submitted Nov 12, 2019. Accepted for publication Jun 11, 2020.

doi: $10.21037 /$ tlcr-19-564

View this article at: http://dx.doi.org/10.21037/tlcr-19-564

\section{Introduction}

Since surgically resected non-small cell lung cancer (NSCLC) cases account for the majority of long-term survivors among total lung cancer population, researchers investigated the role of adjuvant chemotherapy in early stage NSCLC for survival outcomes. Between late 1990s and early 2000s, several large phase III trials were conducted internationally (1-6). Meta-analysis of the studies using cisplatin-based adjuvant chemotherapy demonstrated that adjuvant chemotherapy improves 5 -year overall survival by approximately $5 \%$ over surgery alone in stage II-III (7). A subset analysis within stage IB later showed that adjuvant chemotherapy was associated with higher survival rates in patients with tumors $\geq 4 \mathrm{~cm}$ in diameter (8). Use of adjuvant 
chemotherapy in this setting became standard management in mid 2000s. Thereafter, use of adjuvant chemotherapy in stage II-III NSCLC increased. Despite hesitancy in prescribing chemotherapy for elderly populations, its use was associated with improved survival in elderly groups in meta-analysis and retrospective studies $(9,10)$.

However, use of adjuvant chemotherapy remained low in elderly patients between the ages of 70-80 as compared to younger counterparts (age 66-69) according to SEERMedicare database analysis (11). Although use of adjuvant chemotherapy was reportedly increased from 2003 to 2008 (12), recent trends after 2010 are unknown. While younger populations have adopted adjuvant chemotherapy, elderly groups in modern ages may not accept cytotoxic chemotherapy in the adjuvant setting due to toxicity concerns. This study focused on identifying recent trends in use of adjuvant chemotherapy in resected stage II-III NSCLC. We present the following article in accordance with the STROBE reporting checklist (available at http:// dx.doi.org/10.21037/tlcr-19-564).

\section{Methods}

SEER is a publicly available cancer research resource that collects data on cancer cases since 1973 from United States state-wide cancer registries (1). It represents about $28 \%$ of the US population, including 18 cancer registries. The SEER database contains information on patient demographics, clinical characteristics, tumor stage, first course treatment, and survival data (13). This population study used SEER-18 dataset with SEER* stat v. 8.3.5 software (14-17).

Surgically resected, pathologically confirmed NSCLC cases that were diagnosed between 2004 and 2015 with pathologic stage II-III were identified. AJCC $6^{\text {th }}$ version of TNM staging system, instead of $7^{\text {th }}$ or $8^{\text {th }}$ versions, was used because of availability throughout the period of diagnosis. Information on age, sex, race, histology, presence or absence of chemotherapy in the first course treatment were collected. Cases where chemotherapy use was unknown were assigned into no/unknown category.

Incidence of chemotherapy was assessed according to sex (male $v s$. female), race (white $v s$. others), age (20-69 vs. 7079 vs. 80+), year of diagnosis (2004-2009 vs. 2010-2015), histology (adenocarcinoma vs. others), and pathologic stage (II vs. III). SEER dataset does not define the timing of chemotherapy in relation to surgery, e.g., neoadjuvant, adjuvant, although it counts only for first course treatment.
Information about systemic treatment for recurrent/ metastatic setting was not available. Elderly patients with age $70+$ were then divided into two groups (70-79 vs. $80+$ ) for subset analyses.

Univariate and multivariate analyses were conducted using JMP version 13 (SAS Institute, Cary, NC, USA). A two-tailed $\mathrm{P}$ value less than 0.05 was considered as statistically significant.

This is a population study that involves no identifiable information for individuals throughout the analyses. This study was reviewed by the institutional review board and was considered exempt from human subject research.

\section{Results}

A total of 35,009 cases were selected for the analysis. Clinical characteristics are shown in Table 1. In total, 19,951 (57.0\%) patients received chemotherapy. Its use was more frequent in female, non-white race, age 20-69, year of diagnosis between 2010 and 2015, adenocarcinoma histology, and stage III groups per univariate analysis.

Multivariate analysis demonstrated that younger age, recent year of diagnosis, adenocarcinoma histology, and stage III showed significantly higher rates of chemotherapy use (Table 2). Of note, young age [20-69] and recent diagnosis [year 2010-2015] had 2.67- and 1.27-fold higher incidence of chemotherapy use, respectively, per multivariate analyses. Subgroup analysis in age 70+ also demonstrated that the same variables including younger age [70-79] were associated with higher incidence of chemotherapy (Tables S1,S2).

Use of chemotherapy in the overall population increased by $12.9 \%$, from $49.5 \%$ in 2004 to $62.4 \%$ in 2015 (Table 3). This increase was more prominent in age $70-79(18.3 \%$, from $39.9 \%$ to $58.2 \%)$ than in age $20-69(11.0 \%$, from $59.1 \%$ to $70.2 \%)$ and age $80+(11.3 \%$, from $18.3 \%$ to 29.6\%) (Figure 1).

Increase in use of chemotherapy in the age 70-79 group was greater than in other age groups regardless of stage or histology (Table 3, Figures 2,3). It was more prominent in stage II ( $24.3 \%$ increase, from $33.6 \%$ to $57.9 \%)$. In patients age 80 and older, use of chemotherapy remains low (approximately 30\%) and mildly increased over the decades.

To determine if increased use of chemotherapy resulted in improved survival, we conducted a survival analysis by determining 5-year survival rate (Figure 4). Our analysis was limited by available data up to year 2011. Analysis of all age groups showed that 5 -year overall survival only mildly 
Table 1 Characteristics of the patients with p-stage II-III diagnosed between 2004 and 2015

\begin{tabular}{|c|c|c|c|c|}
\hline Variable & \multicolumn{3}{|c|}{ Perioperative chemotherapy } & Chi-square $P$ value \\
\hline Total & 15,058 & 19,951 & 57.0 & \\
\hline Sex & & & & 0.009 \\
\hline Male & 8,139 & 10,503 & 56.3 & \\
\hline Race & & & & $<0.0001$ \\
\hline White & 12,901 & 16,649 & 56.3 & \\
\hline Others & 2,157 & 3,302 & 60.5 & \\
\hline Age & & & & $<0.0001$ \\
\hline $80+$ & 2,408 & 804 & 25.0 & \\
\hline Year of diagnosis & & & & $<0.0001$ \\
\hline 2004-2009 & 8,292 & 9,883 & 54.4 & \\
\hline 2010-2015 & 6,766 & 10,068 & 59.8 & \\
\hline Histology & & & & $<0.0001$ \\
\hline Adenocarcinoma & 5,646 & 8,564 & 60.3 & \\
\hline Others & 9,412 & 11,387 & 54.7 & \\
\hline Stage & & & & $<0.0001$ \\
\hline
\end{tabular}

Table 2 Univariate and multivariate analyses for association with use of perioperative chemotherapy

\begin{tabular}{|c|c|c|c|c|c|c|}
\hline Variable & \multicolumn{3}{|c|}{ Univariate analysis } & \multicolumn{3}{|c|}{ Multivariate analysis } \\
\hline Sex (male vs. female) & 0.95 & $0.91-0.99$ & 0.009 & 0.98 & $0.94-1.03$ & 0.458 \\
\hline Race (white vs. others) & 0.84 & $0.79-0.89$ & $<0.0001$ & 0.95 & $0.90-1.01$ & 0.131 \\
\hline Age (20-69 vs. $70+)$ & 2.66 & $2.54-2.78$ & $<0.0001$ & 2.67 & $2.56-2.79$ & $<0.0001$ \\
\hline Histology (adenocarcinoma vs. others) & 1.25 & $1.20-1.31$ & $<0.0001$ & 1.23 & $1.17-1.28$ & $<0.0001$ \\
\hline Stage (III vs. II) & 1.35 & $1.29-1.41$ & $<0.0001$ & 1.33 & $1.27-1.39$ & $<0.0001$ \\
\hline
\end{tabular}

OR; odds ratio, $\mathrm{Cl}$; confidence interval. 
Table 3 Increase in use of chemotherapy from 2004 to 2015

\begin{tabular}{lcccc}
\hline \multirow{2}{*}{ Category } & \multicolumn{3}{c}{ Age group } & \multirow{2}{*}{ Total } \\
\cline { 2 - 4 } & $20-69$ & $70-79$ & $80+$ & \\
\hline Total & $11.0 \%$ & $18.3 \%$ & $11.3 \%$ & $12.9 \%$ \\
Stage II & $16.3 \%$ & $24.3 \%$ & $12.0 \%$ & $18.0 \%$ \\
Stage III & $7.0 \%$ & $14.1 \%$ & $9.2 \%$ & $9.0 \%$ \\
Adenocarcinoma & $12.4 \%$ & $18.2 \%$ & $5.0 \%$ & $13.6 \%$ \\
Non-adenocarcinoma & $10.0 \%$ & $18.4 \%$ & $14.9 \%$ & $12.2 \%$ \\
\hline
\end{tabular}

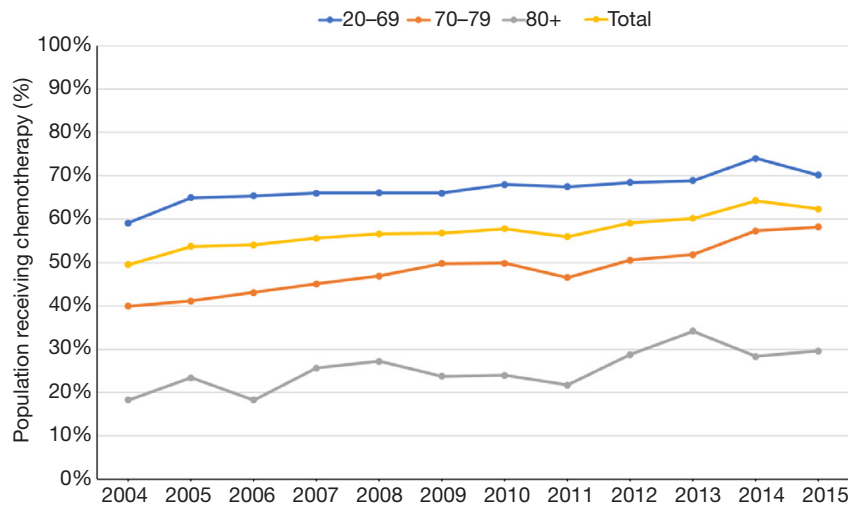

Figure 1 Trends in use of perioperative chemotherapy in stage IIIII by age. The median \% of population receiving chemotherapy was plotted. Total, all age groups.

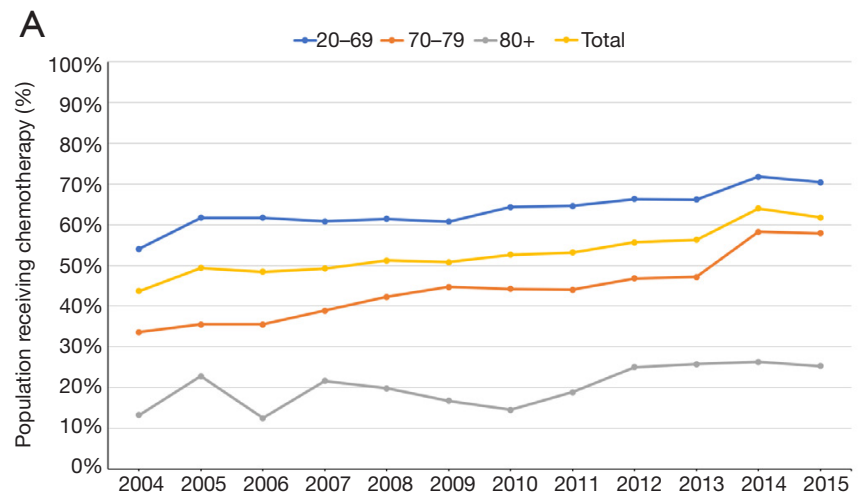

increased by $5.6 \%$, from $37.3 \%$ in 2004 to $42.9 \%$ in 2011 . In age 20-69, 70-79, 80+ groups, 5-year overall survival increased by $5.9 \%, 7.6 \%$, and $1.0 \%$ respectively.

\section{Discussion}

Researchers design and execute trials in various clinical settings. They are expected to address clinically relevant questions to provide guidance for clinicians. However, patient selection for these studies is often skewed by patient selection based on clinical characteristics for safety reasons. Elderly populations are often underrepresented in clinical trials because physician investigators are reluctant to enroll them due to safety concerns. These patients often have poor performance status and/or significant comorbidities that might influence toxicity analyses.

Adjuvant chemotherapy became standard of care in the setting of surgically resected stage II-III and large $(\mathrm{T} \geq 4 \mathrm{~cm})$ stage I based on several phase III trials and metaanalyses (2-8,18-20). However, only a small number of elderly patients were enrolled in the studies. A retrospective study using SEER data showed that chemotherapy use in the age $66+$ population was approximately $30-40 \%$ in 2003-2006 despite increasing since 2000 (11). Recent trends in the use of adjuvant chemotherapy have not yet been reported.

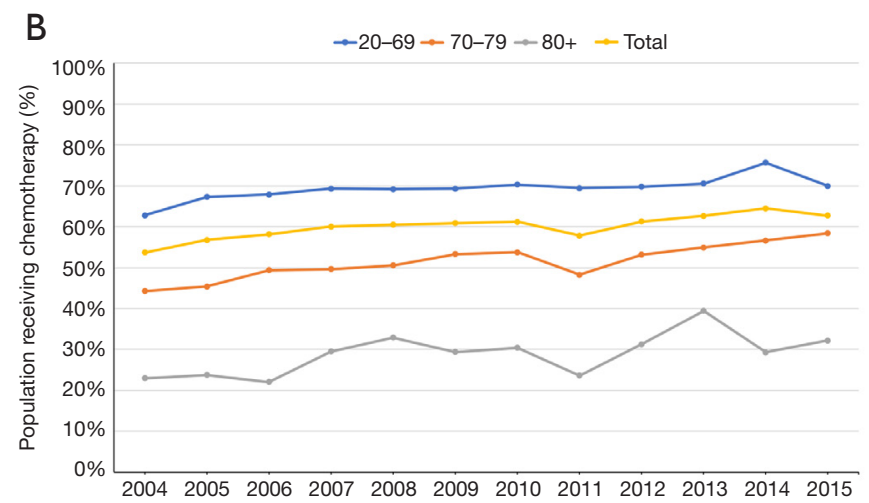

Figure 2 Trends in use of perioperative chemotherapy by stage and age. The median \% of population receiving chemotherapy was plotted. (A) Stage II; (B) stage III. Total, all age groups. 

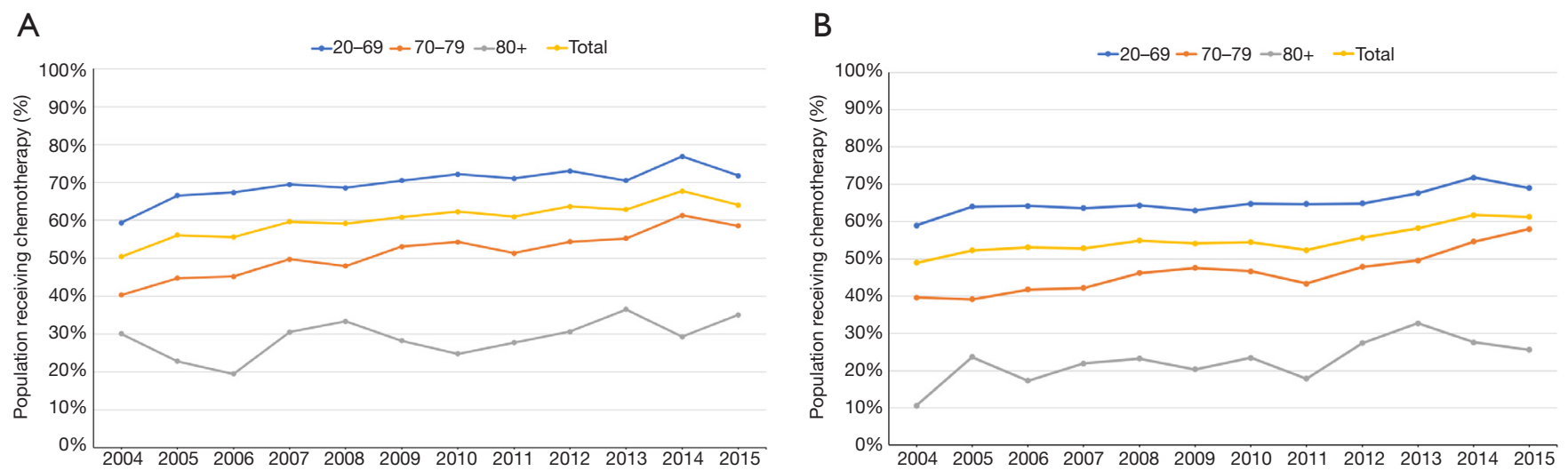

Figure 3 Trends in use of perioperative chemotherapy by histology and age. The median \% of population receiving chemotherapy was plotted. (A) Adenocarcinoma; (B) non-adenocarcinoma. Total, all age groups.

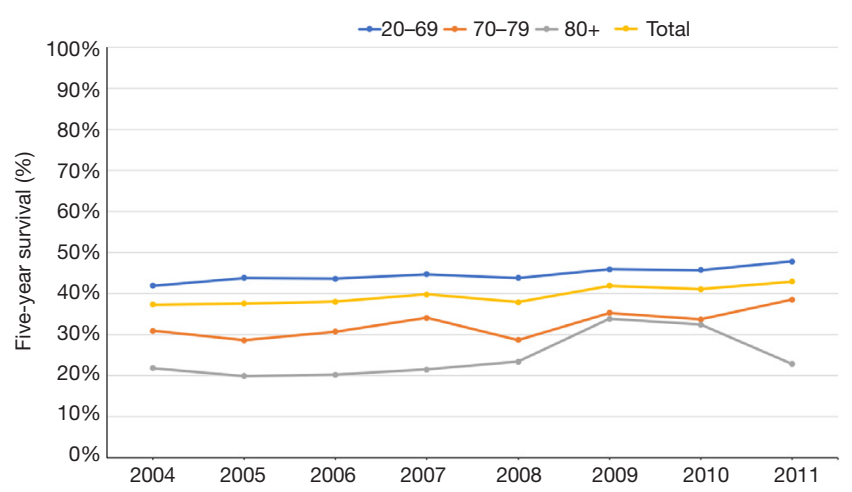

Figure 4 Trends in 5 -year overall survival in stage II-III cases by age. The five-year survival rate (\%) was plotted according to year of diagnosis. Total, all age groups.

Our study demonstrates that increased use of chemotherapy was greater in the age 70-79 group than in other age groups. The increase in the age 70-79 group was also more prominent in patients with stage II disease. Chemotherapy use remained low (approximately 30\%) in the age $80+$ group (11). Although the SEER database only provides presence or absence of chemotherapy use, we consider the majority of cases to have received adjuvant chemotherapy based on previous SEER-Medicare analysis data, which indicates that only $3.9 \%$ of patients received neoadjuvant chemotherapy (12). The increase in 5 -year overall survival was modest in the age 20-69 and 70-79 groups (Figure 4). There is minimal increase in 5-year overall survival in the age $80+$ group.

We, however, acknowledge limitations in this study. As discussed previously, the SEER dataset does not define the timing of chemotherapy in relation to surgery, e.g., neoadjuvant, adjuvant, although it was classified into the "yes" category only if chemotherapy was delivered as first course of treatment. We assume that most patients probably received adjuvant chemotherapy based on previous reports (12). We did not exclude patients who died within the immediate post-surgical period. No detailed information about chemotherapy (e.g., number of cycles or regimens) was available. The analyses in this study were intended to review populations in the US for which Caucasians dominate. Trends in other ethnic groups or nations are unknown.

The use of the AJCC $6^{\text {th }}$ version of staging system may limit the interpretation. Because SEER adopted the AJCC $7^{\text {th }}$ version in 2010, cases prior to 2010 have never been staged based on the $7^{\text {th }}$ version. We therefore were limited to use of the $6^{\text {th }}$ version due to its consistent availability throughout the study period. Major differences between the $6^{\text {th }}$ and $7^{\text {th }}$ versions in surgical N0 cases were tumors with $\mathrm{T}>7 \mathrm{~cm}(\mathrm{~T} 2 /$ stage IB $v s$. T3/stage IIB, $\mathrm{n}=457)$ and $\mathrm{T}=5-7 \mathrm{~cm}$ (T2/stage IB $v s$. T2 b/stage IIA, $\mathrm{n}=1,016)$, respectively (21). These tumors will be classified as stage II or III in the $8^{\text {th }}$ edition requiring adjuvant chemotherapy. These cases staged as stage $\mathrm{I}$ according to $6^{\text {th }}$ edition were not included in the current analysis. However, previous adjuvant trials using the $6^{\text {th }}$ version demonstrated chemotherapy benefit in node positive cases. Because all the three versions of AJCC staging systems take N1+ for stage II and higher, most cases that benefit from chemotherapy in the $6^{\text {th }}$ version remain stage II-III.

Nevertheless, we believe this study assists practicing oncologists in determination of whether to use adjuvant 
chemotherapy in elderly populations. Further research is needed to determine whether adjuvant chemotherapy should be recommended in age $80+$ group.

\section{Conclusions}

This study suggests that with recent guideline recommendations, oncologists are increasingly offering adjuvant chemotherapy to patients aged 70-79, and increased use of adjuvant chemotherapy led to modest improvement in overall survival in patients ages 70-79. However, oncologists still hesitate to treat age $80+$ group with adjuvant chemotherapy.

\section{Acknowledgments}

We thank the Parkview Research Center for administrative support.

Funding: None.

\section{Footnote}

Reporting Checklist: The authors have completed the STROBE Reporting Checklist. Available at http://dx.doi. org/10.21037/tlcr-19-564

Conflicts of Interest: All authors have completed the ICMJE uniform disclosure form (available at http://dx.doi. org/10.21037/tlcr-19-564). TK reports personal fees from Merck and Boehringer Ingelheim outside the submitted work. The other authors have no conflicts of interest to declare.

Ethical Statement: The authors are accountable for all aspects of the work in ensuring that questions related to the accuracy or integrity of any part of the work are appropriately investigated and resolved. Institutional Review Board at Augusta University gave exemption because the study was deemed not to constitute human subject research.

Open Access Statement: This is an Open Access article distributed in accordance with the Creative Commons Attribution-NonCommercial-NoDerivs 4.0 International License (CC BY-NC-ND 4.0), which permits the noncommercial replication and distribution of the article with the strict proviso that no changes or edits are made and the original work is properly cited (including links to both the formal publication through the relevant DOI and the license).
See: https://creativecommons.org/licenses/by-nc-nd/4.0/.

\section{References}

1. Cancer Stat Facts: Lung and Bronchus Cancer. National Cancer Institute Surveillance, Epidemiology, and End Results Program. Available online: https://seer.cancer.gov/ statfacts/html/lungb.html, Accessed on August 14, 2019.

2. Arriagada R, Bergman B, Dunant A, et al. Cisplatinbased adjuvant chemotherapy in patients with completely resected non-small-cell lung cancer. $\mathrm{N}$ Engl J Med 2004;350:351-60.

3. Winton T, Livingston R, Johnson D, et al. Vinorelbine plus cisplatin vs. observation in resected non-small-cell lung cancer. N Engl J Med 2005;352:2589-97.

4. Douillard JY, Rosell R, De Lena M, et al. Adjuvant vinorelbine plus cisplatin versus observation in patients with completely resected stage IB-IIIA non-small cell lung cancer (Adjuvant Navelbine International Trialist Association [ANITA]): A randomised controlled trial. Lancet Oncol 2006;7:719-27.

5. Scagliotti GV, Roldano F, Torri V, et al. Randomized study of adjuvant chemotherapy for completely resected stage I, II, or IIIA non-small cell lung cancer. J Natl Cancer Inst 2003;95:1453-61.

6. Waller D, Peake RJ, Stephens RJ, et al. Chemotherapy for patients with non-small cell lung cancer: The surgical setting of the Big Lung Trial. Eur J Cardiothorac Surg 2004;26:173-82.

7. Pignon JP, Tribodet H, Scagliotti GV, et al. Lung Adjuvant Cisplatin Evaluation: A Pooled Analysis by the LACE Collaborative Group. J Clin Oncol 2008;26:3552-9.

8. Strauss GM, Herndon JE II, Maddaus MA, et al. Adjuvant Paclitaxel Plus Carboplatin Compared With Observation in Stage IB Non-Small-Cell Lung Cancer: CALGB 9633 With the Cancer and Leukemia Group B, Radiation Therapy Oncology Group, and North Central Cancer Treatment Group Study Groups. J Clin Oncol 2008;26:5043-51.

9. Früh M, Rolland E, Pignon JP, et al. Pooled Analysis of the Effect of Age on Adjuvant Cisplatin-Based Chemotherapy for Completely Resected Non-Small-Cell Lung Cancer. J Clin Oncol 2008;26:3573-81.

10. Malhotra J, Mhango G, Gomez JE et al. Adjuvant chemotherapy for elderly patients with stage I non-smallcell lung cancer $\geq 4 \mathrm{~cm}$ in size: an SEER-Medicare analysis. Ann Oncol 2015;26:768-73.

11. Berry MF, Coleman BK, Curtis LH, et al. Benefit of 
Adjuvant Chemotherapy After Resection of Stage II (T12N1M0) Non-Small Cell Lung Cancer in Elderly Patients. Ann Surg Oncol 2015;22:642-8.

12. Schroeder MC, Tienb YY, Wright K, et al. Geographic variation in the use of adjuvant therapy among elderly patients with resected non-small cell lung cancer. Lung Cancer 2016;95:28-34.

13. Komiya T, Guddati AK, Chaaya G. Overview of publications on lung cancer using the SEER database. Respir Investig 2018;56:424-6

14. SEER*Stat Software. National Cancer Institute Surveillance, Epidemiology, and End Results Program. Available online: https://seer.cancer.gov/seerstat/, Accessed on August 15, 2019.

15. Komiya T, Perez RP, Yamamoto S, et al. Primary lung mucoepidermoid carcinoma: analysis of prognostic factors using surveillance, epidemiology and end results program. Clin Respir J 2017;11:847-53

16. Komiya T, Chaaya G, Powell E. Addition of chemotherapy improves overall survival in patients with T2N0M0 nonsmall cell lung cancer undergoing definitive radiation therapy: An analysis of the SEER database. Radiother

Cite this article as: Komiya T, Powell E, Guddati AK. Recent trends in use of adjuvant chemotherapy in elderly stage IIIII non-small cell lung cancer. Transl Lung Cancer Res 2020;9(4):1180-1186. doi: 10.21037/tlcr-19-564
Oncol 2019;131:75-80.

17. Komiya T, Guddati AK, Nakanishi Y. Clear cell adenocarcinoma of the lung: a SEER analysis. Transl Lung Cancer Res 2019;8:187-91.

18. Non-Small Cell Lung Cancer Collaborative Group: Chemotherapy in non-small cell lung cancer:A metaanalysis using updated data on individual patients from 52 randomized clinical trials. BMJ 1995;311:899-909.

19. Hotta K, Matsuo K, Ueoka H, et al. Role of adjuvant chemotherapy in patients with resected non-small-cell lung cancer: reappraisal with a meta-analysis of randomized controlled trials. J Clin Oncol 2004;22:3860-7.

20. Sedrakyan A, Van Der Meulen J, O'Byrne K, et al. Postoperative chemotherapy for non-small cell lung cancer: A systematic review and meta-analysis. J Thorac Cardiovasc Surg 2004;128:414-9.

21. Goldstraw P, Crowley J, Chansky K, et al. The IASLC Lung Cancer Staging Project: Proposals forthe Revision of the TNM Stage Groupings in the Forthcoming (Seventh) Edition of the TNM Classification of Malignant Tumours. J Thorac Oncol 2007;2:706-14. 


\section{Supplementary}

Table S1 Characteristics of the patients with p-stage II-III in age 70 and older

\begin{tabular}{|c|c|c|c|c|}
\hline Variable & \multicolumn{3}{|c|}{ Perioperative chemotherapy } & Chi-square $\mathrm{P}$ value \\
\hline Total & 8,279 & 6,271 & 43.1 & \\
\hline Sex & & & & 0.924 \\
\hline Male & 4,461 & 3,374 & 43.1 & \\
\hline Race & & & & 0.132 \\
\hline White & 7,308 & 5,484 & 42.9 & \\
\hline Others & 971 & 787 & 44.8 & \\
\hline Age & & & & $<0.0001$ \\
\hline Year of diagnosis & & & & $<0.0001$ \\
\hline 2004-2009 & 4,475 & 2,921 & 39.5 & \\
\hline 2010-2015 & 3,804 & 3,350 & 46.8 & \\
\hline Histology & & & & $<0.0001$ \\
\hline Adenocarcinoma & 3,093 & 2,661 & 46.2 & \\
\hline Others & 5,186 & 3,610 & 41.0 & \\
\hline Stage & & & & $<0.0001$ \\
\hline Stage II & 3,753 & 2,340 & 38.4 & \\
\hline
\end{tabular}

Table S2 Univariate and multivariate analysis in prediction of use of perioperative chemotherapy in age 70 and older

\begin{tabular}{|c|c|c|c|c|c|c|}
\hline Variable & \multicolumn{3}{|c|}{ Univariate analysis } & \multicolumn{3}{|c|}{ Multivariate analysis } \\
\hline Sex (male vs. female) & 1.00 & $0.93-1.06$ & 0.924 & 1.03 & $0.96-1.10$ & 0.391 \\
\hline Race (white vs. others) & 0.93 & $0.84-1.02$ & 0.132 & 0.99 & $0.89-1.09$ & 0.775 \\
\hline Age (70-79 vs. $80+)$ & 2.79 & $2.55-3.05$ & $<0.0001$ & 2.83 & $2.59-3.09$ & $<0.0001$ \\
\hline Histology (adenocarcinoma vs. others) & 1.24 & $1.16-1.32$ & $<0.0001$ & 1.25 & $1.16-1.34$ & $<0.0001$ \\
\hline Stage (III vs. II) & 1.39 & $1.30-1.49$ & $<0.0001$ & 1.39 & $1.30-1.49$ & $<0.0001$ \\
\hline
\end{tabular}

OR; odds ratio, $\mathrm{Cl}$; confidence interval. 